\title{
Aa. Vv., Actualités de Tristan. Actes du Colloque international
}

\section{Cecilia Rizza}

\section{(2) OpenEdition}

1 Journals

\section{Edizione digitale}

URL: https://journals.openedition.org/studifrancesi/39246

DOI: 10.4000/studifrancesi.39246

ISSN: 2421-5856

\section{Editore}

Rosenberg \& Sellier

\section{Edizione cartacea}

Data di pubblicazione: 1 décembre 2004

Paginazione: 358-359

ISSN: 0039-2944

\section{Notizia bibliografica digitale}

Cecilia Rizza, «Aa. Vv., Actualités de Tristan. Actes du Colloque international», Studi Francesi [Online], 143 (XLVIII | II) | 2004, online dal 30 novembre 2015, consultato il 19 mai 2021. URL: http:// journals.openedition.org/studifrancesi/39246 ; DOI: https://doi.org/10.4000/studifrancesi.39246

Questo documento è stato generato automaticamente il 19 mai 2021.

\section{(c) $($ i) $(9)$}

Studi Francesi è distribuita con Licenza Creative Commons Attribuzione - Non commerciale - Non opere derivate 4.0 Internazionale. 


\title{
Aa. Vv., Actualités de Tristan. Actes $\mathrm{du}$ Colloque international
}

\author{
Cecilia Rizza
}

\section{NOTIZIA}

AA. VV., Actualités de Tristan. Actes du Colloque international (22, 23 et 24 novembre 2001), «Littérales», n. spéc. n. 3, 2003, pp. 342.

1 Sono qui pubblicate le comunicazioni presentate al convegno organizzato presso l'Università di Parigi- Nanterre in occasione del centenario della nascita di Tristan l'Hermite. Si tratta di una ventina di contributi che riguardano tutta l'opera di Tristan, divisi in tre grandi gruppi: Tristan dans son temps. Tristan en son doute. Tristan aujourd'hui La suddivisione non impedisce di cogliere un denominatore comune che si riconosce, sia nell'analsi del rapporto con gli autori del tempo (L. PICCIOLA, Deux drammaturgies de la jalousie. pp. 13-30 su due pièces di Calderon e di Tristan e V. STBERG, «Le Parasite» ou le sens du jeu. pp. 103-115 che mette a confonto la commedia di Tristan con l'olimpia di Della Porta) sia in relazione ad una tradizione letteraria che, specie nella poesia, ha profonde radici francesi e italiane (L. GROVE, Tristan et la tradition emblématique. pp. 89-102; M. -O. SWEETSER, Paysage, jardins et parcs miroirs de l'affectivité et du goût, pp. 135-150; Ch. MC CALL PROBES, «N'ois-tu pas soupirer Zéphire», pp. 241-259; G. MATHIEU CASTELLANI, La mythologie de Tristan, pp. 277-293). Questo denominatore comune, questa più profonda unità appare con maggiore evidenza nell'interpretazione del Page disgracié che propone S. ROBIC (pp. 261-273) nel richiamo allo stoicismo formulato da P. DANDREY a proposito de La folie du sage (pp. 179-194) e nell'articolo di F. D'ANGELO su Humanisme chrétien et libre pensée dans «La mort de Sénèque (pp. 229-239). Punto d'incontro per tutti questi contributi è il riferimento ad una problematica profonda che fa di Tristan un testimone esemplare di quella crisi di valori che caratterizza la cultura francese della prima metà del secolo. Da questo punto di vista acquistano particolare interesse anche quei Principes de cosmographie di cui si occupa I. PATIN (pp. 117-134) 
che condivide l'attribuzione a Tristan formulata da F. GRAZIANI e l'analisi di B. DONNÉ che studia il rapporto tra galanteria e morale nella Carte du Tendre (pp. 211-228); ma anche quei testi di Tristan che anticipano i futuri sviluppi di un genere letterario destinato ad avere grande fortuna nel corso del secolo (R. ZAISER) «La Page disgracié» de Tristan l'Hermite et la naissance du roman moderne en France, pp. 313-324) o tentano di conciliare la sua esperienza di poeta alle esigenze della drammaturgia (G. PEUREuX, Stances poétiques et stances dramatiques: les enjeux d'une réécrituré, pp. 153-166). Trovano posto in questi Atti. altri importanti contributi sul grotesque nella poesia e nel teatro (D. SCHOLL, Un mixte composé de lumière et de fange, pp. 61-77) sull' autobiografia nel Page disgracié (M. BOMBARD, pp. 195-210) e sempre sul Page disgracié e il genere narrativo l'articolo di E. DESILES (pp. 79-88) . Per quanto poi riguarda la poesia che occupa lo spazio maggiore di questo volume, - e questa presenza privilegiata non è senza significato -, citeremo ancora gli articoli di A. GENETIOT (Le lyrisme tristanien: une idylle héroïque en éclats?, pp. 31-60) e di R. GANIM (L'excitation insolite: la perversité amoureuse chez Tristan, pp. 167-178) e il saggio di. V. ADAM su Les Univers imaginaires de Tristan l'Hermite, pp. 295-312) che si pone sulla linea critica sperimentata dall'Autrice nel volume più sopra recensito. Chiude questo ampio ed estremamente ricco omaggio a Tristan e a tutte le varie espressioni della sua creazione artistica, a cui si deve anche il merito di aprire nuovi orizzonti per future ricerche, una storia ancorchè sommaria della fortuna dello scrittore nel tempo (pp. 325-342), ad opera di S. Berregard. 